\title{
ANALISA DAN PERANCANGAN WEBSITE SDN KARAWANG KULON
}

\author{
${ }^{1}$ Erlina Noviyanthi, ${ }^{2}$ Karya Suhada \\ Erlina.novi@gmail.com, karya@ rosma.ac.id
}

\begin{abstract}
Abstrak
Ilmu pengetahuan dan teknologi informasi berkembang cukup pesat dan menghasilkan inovasi-inovasi baru yang senantiasa terus berubah ke arah yang lebih baik. Informasi menjadi kata kunci dalam berbagai aspek kehidupan. Siapa yang dapat menguasai informasi, baik penguasaan dalam proses penyajian, maupun mendapatkan, ia akan bisa tampil survive di tengah persaingan yang sedemikian ketat. Dengan alasan inilah perhatian terhadap proses informasi menjadi sangat di tekankan. Sistem Informasi Sekolah adalah suatu tatanan yang berhubungan dengan penyampaian informasi akan kebutuhan informasi sekolah dari berbagai pihak. Tujuan dari perancangan ini diharapkan dapat memberikan kemudahan bagi berbagai pihak dalam memperoleh informasi secara lebih cepat dan akurat.

Metodologi yang digunakan penulis dalam pembahasan ini adalah metode studi pustaka yang meliputi mengumpulkan, membaca dan mempelajari buku-buku yang menunjang materi pembuatan skripsi melalui buku-buku, serta artikel-artikel internet. Selain itu digunakan juga metode perancangan dan merancangan layar-layar tampilan yang akan dipakai dalam website yang dibangun, mengevaluasi sistem dengan cara di implementasikan. Sebagai rancangannya tool yang digunakan yaitu Macromedia Dreamweaver dan MySQL sebagai databasenya. Dengan demikian penulis berharap dengan adanya website ini, dapat meningkatkan pelayanan akan suatu informasi kepada seluruh pihak, baik saat ini maupun di masa yang akan datang. Dan benar-benar dapat bermanfaat bagi para guru, siswa maupun staf-staf yang bekerja.
\end{abstract}

Kata Kunci : Sistem Informasi, Sekolah, Website

\begin{abstract}
Science and information technology develop quite rapidly and produce new innovations that always change in a better direction. Information becomes a key word in various aspects of life. Who can master information, whether mastery in the presentation process, or get, he will be able to appear to survive in the midst of such tight competition. It is for this reason that attention to the information process is emphasized. The School Information System is an order related to the delivery of information on school information needs from various parties. The purpose of this design is expected to provide convenience for various parties to obtain information more quickly and accurately.

The methodology used by the author in this discussion is the literature study method which includes collecting, reading and studying books that support thesis-making materials through books, as well as internet articles. Besides that, it is also used a method of designing and designing display screens that will be used in the website that is built, evaluating the system in a way that is implemented. As a design tool used is Macromedia Dreamweaver and MySQL as the database. Thus the authors hope that with this website, it can improve the service of information to all parties, both now and in the future. And really can be useful for teachers, students and working staff.
\end{abstract}

Keywords: Information Systems, Schools, Websites

Jurnal Interkom Vol. 12 No. 1-April 2017 


\section{Pendahuluan}

Ilmu pengetahuan dan teknologi informasi berkembang cukup pesat dan menghasilkan inovasi-inovasi baru yang senantiasa terus berubah ke arah yang lebih baik. Informasi menjadi kata kunci dalam berbagai aspek kehidupan. Siapa yang dapat menguasai informasi, baik penguasaan dalam proses penyajian, maupun mendapatkan, ia akan bisa tampil survive di tengah persaingan yang sedemikian ketat. Dengan alasan inilah perhatian terhadap proses informasi menjadi sangat di tekankan.

Pembangunan sumber daya manusia, pada bidang pendidikan merupakan sarana dan wahana yang sangat baik dalam pembinaan sumber daya manusia. Oleh karena itu pendidikan perlu mendapat perhatian yang lebih serius baik itu oleh pemerintah, keluarga maupun pengelola pendidikan khususnya.

Perkembangan teknologi yang semakin pesat, sarana dan prasarana pendidikan pun harus mengikutinya, salah satunya dengan media komputerisasi yaitu internet. Dengan internet, dimana siswa maupun guru dapat mengakses ilmu pengetahuan dan informasi kapan saja dan dimana saja.

Banyak sekali manfaat dari internet. Salah satunya adalah pembuatan sistem informasi berbasis web, sistem ini akan menampilkan informasi mengenai hal-hal sesuai dengan apa yang dikehendaki oleh pembuat. Sebuah sistem informasi yang baik tentunya mampu menjalankan semua hal yang berkaitan dengan penyelenggaraan hal-hal spesifik.

Saat ini masyarakat membutuhkan segala informasi yang serba cepat dan akurat sehingga aplikasi website salah satunya dapat dimanfaatkan oleh pihak SDN Karawang Kulon sebagai sarana promosi, komunikasi dan interaksi dengan masyarakat, masyarakat juga di mudahkan dalam hal mendapatkan informasi mengenai SDN Karawang Kulon. Selain itu hal ini dimaksudkan untuk lebih menambah citra SDN Karawang Kulon di kalangan masyarakat umum. Dari latar belakang masalah di atas maka peneliti mengangkat judul "Analisa Dan Perancangan Website SDN Karawang Kulon.”

\section{Tinjauan Pustaka}

\section{Pengertian Sistem}

Menurut McLeod Jr R (1995,13), “sistem adalah sekelompok elemen yang terintegrasi dengan maksud yang sama untuk mencapai suatu tujuan".

\section{Pengertian Informasi}

Menurut Jogiyanto HM,Akt,MBA,ph.D. $(2001,8)$, "informasi adalah data yang diolah menjadi bentuk yang lebih berguna dan lebih berarti bagi penerimanya yang menggambarkan suatu kejadian-kejadian (event) yang nyata (fact) yang digunakan untuk pengambilan keputusan".

\section{Pengertian Sistem Informasi}

Menurut Wilkinson (1993,4), "sistem informasi adalah suatu kerangka kerja yang man sumber daya (manusia, komputer) dikoordinasikan untuk mengubah masukan (data) menjadi keluaran (informasi), guna mencapai sasaran-sasaran perusahaan".

Menurut Hall J A (2001,7), "sistem informasi adalah sebuah rangkaian prosedur formal diamana data dikelompokan, diproses menjadi informasi, dan didistribusikan kepada pemakai".

\section{Pengertian Manajemen Berbasis Sekolah}

Manajemen Berbasis Sekolah (MBS) merupakan konsep pengelolaan sekolah yang ditujukan untuk meningkatkan mutu pendidikan di era desentralisasi pendidikan.

Manajemen Berbasis Sekolah (MBS) pada hakikatnya adalah penyerasian sumber daya yang dilakukan secara mandiri oleh sekolah dengan melibatkan semua pemangku kepentingan yang terkait dengan sekolah secara langsung dalam proses pengambilan keputusan untuk memenuhi kebutuhan peningkatan mutu sekolah atau untuk mencapai tujuan pendidikan nasional.

\section{Pengertian Database}

Menurut Charles Wiliam (1994,4), "database adalah suatu tempat dimana informasi disimpan". Database juga merupakan komponen terpenting dalam pembangunan sistem informasi, karena tempat untuk 
menampung dan mengkoordinasikan seluruh data yang ada dalam sistem, sehingga dapat dieksplorasi untuk menyusun informasiinformasi dalam berbagai bentuk.

\section{Metode Penelitian}

Peneliti telah mengumpulkan data dan informasi yang diperlukan untuk menyelesaikan penelitian dengan menggunakan sebuah metode penelitian yang mencakup 2 (dua) metode yaitu sebagai berikut :

a. Metode Analisis

Analisis sistem dilakukan dengan beberapa tahapan yaitu :

1. Melakukan survei terhadap lokasi yang akan dijadikan bahan pembuatan website.

2. Mengidentifikasi kebutuhan informasi.

b. Metode Perancangan

Dalam skripsi ini metode perancangan yang digunakan adalah metode perancangan terstuktur melalui tahapan-tahapan sebagai berikut :

1. Pembuatan rancangan web sekolah

2. Pembuatan Sistem Transisi Diagram (STD).

\section{Hasil Penelitian dan Pembahasan}

\section{Rencana implementasi}

Rencana implementasi untuk pemasangan Situs Web SDN Karawang Kulon, maka kita memerlukan beberapa komponen. Berbagai macam kebutuhan juga diperlukan dalam pembuatan website ini. Komponen-komponen tersebut antara lain : hardware, software dan brainware.

\section{Usulan Hardware dan Software}

Membangun sebuah sistem yang baru yakni sistem yang berbasis website, maka diperlukan sarana penunjang berupa hardware, software dan brainware. Adapun hardware dan software yang dibutuhkan oleh sistem diantaranya :

a. Spesifikasi perangkat keras (Hardware)

1. Processor intel Pentium Core 2 Duo

2. Memory $1 \mathrm{~Gb}$

3. Harddisk $160 \mathrm{~Gb}$
4. Monitor
5. Scanner
6. Modem

b. Spesifikasi perangkat lunak (Software)

1. Web browser (Internet explorer, Opera Mini, Mozilla Firefox)

2. Macromedia Dreamweaver

3. MySQL untuk database

4. Windows XP

\section{Perancangan layar Front End}

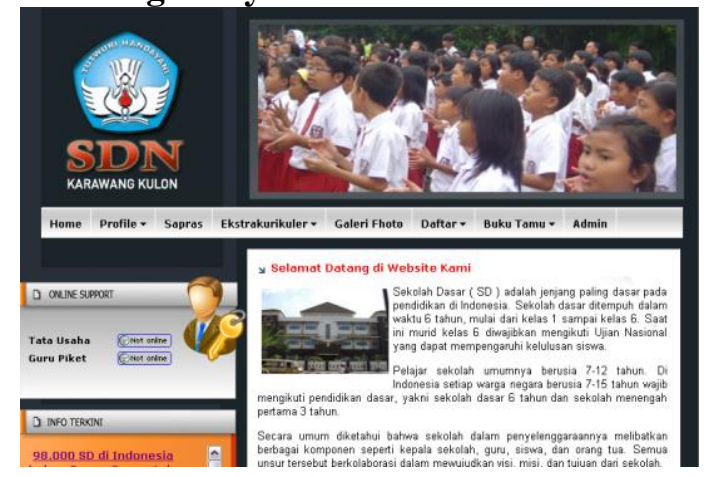

Gambar 1. Tampilan Layar Menu Utama

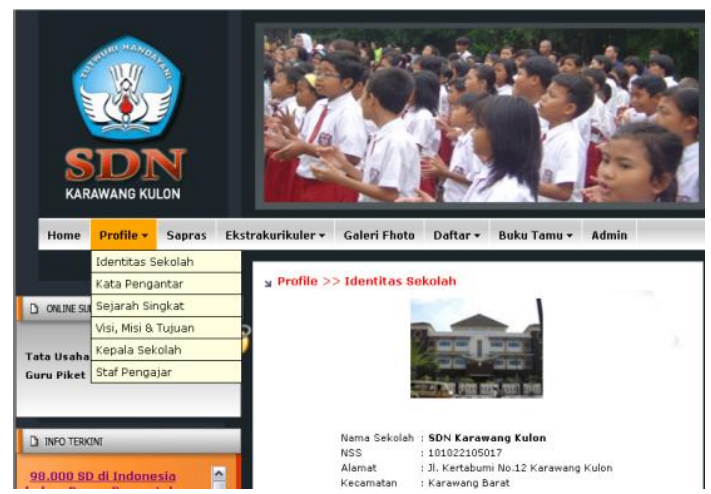

Gambar 2. Tampilan Layar Profile-Identitas Sekolah

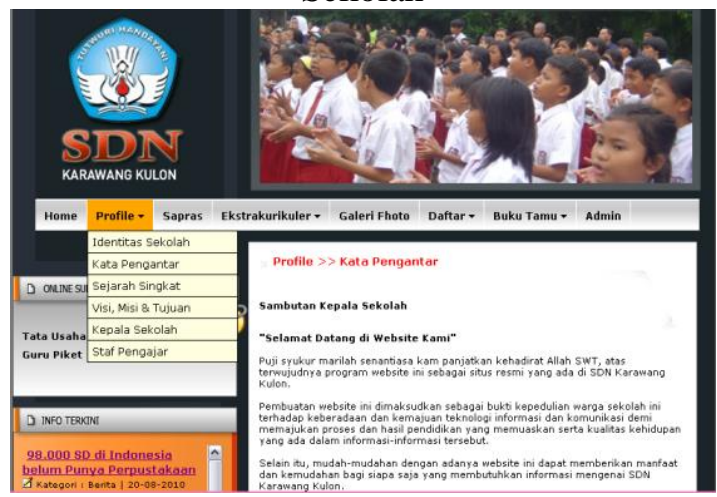

Gambar 3. Tampilan Layar Profile-Kata Pengantar 


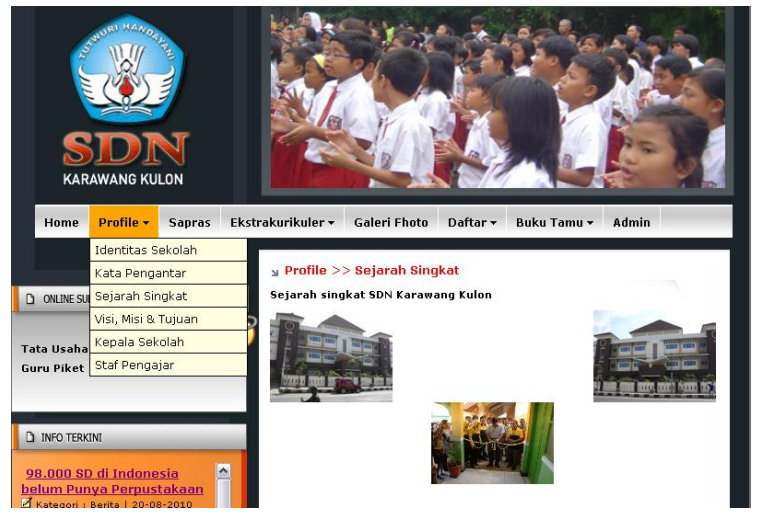

Gambar 4. Tampilan Layar Profile-Sejarah Singkat

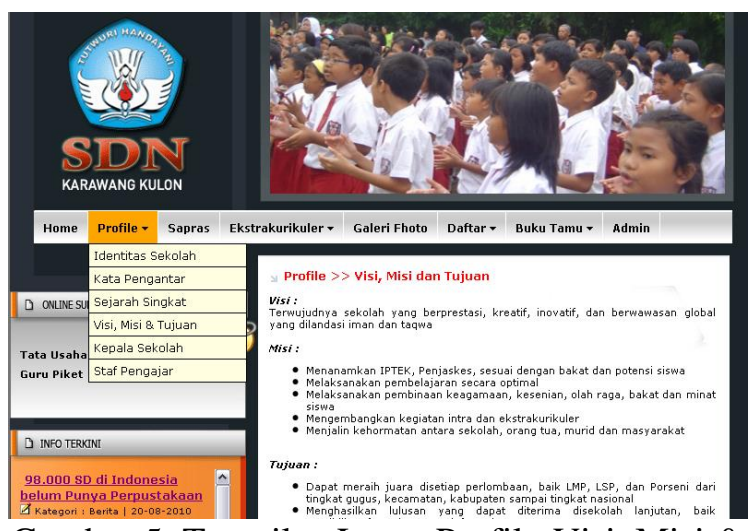

Gambar 5. Tampilan Layar Profile-Visi, Misi \& Tujuan

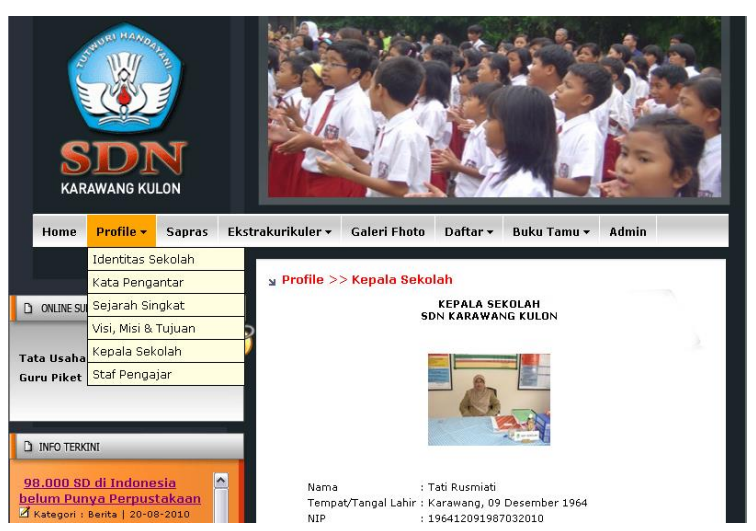

Gambar 6. Tampilan Layar Profile-Kepala Sekolah

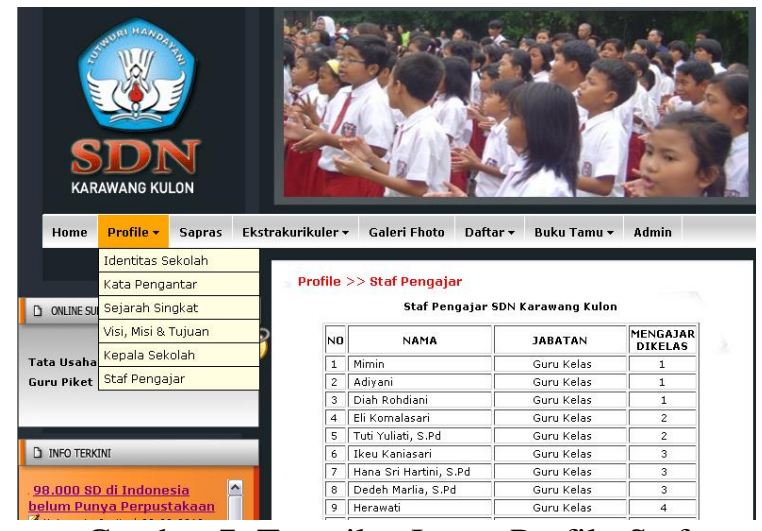

Gambar 7. Tampilan Layar Profile-Staf Pengajar

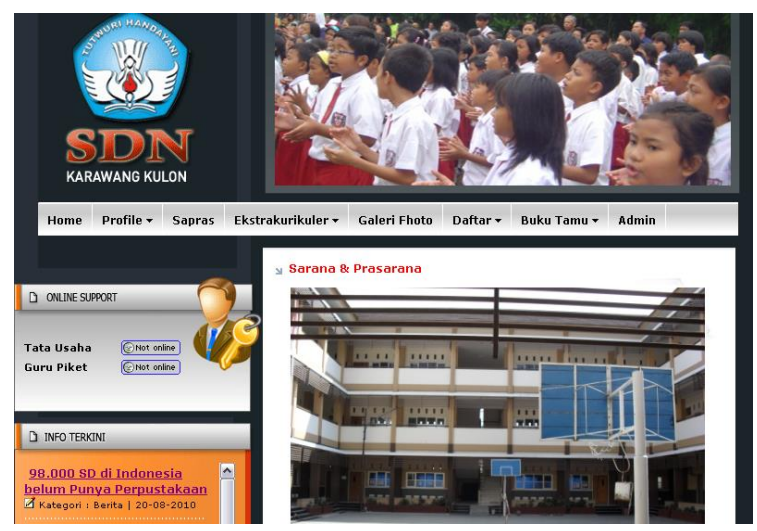

Gambar 8. Tampilan Layar Sapras
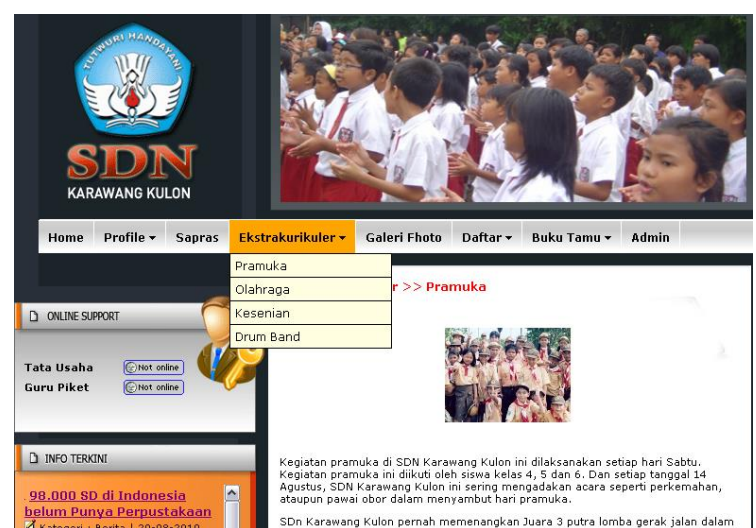

Gambar 9. Tampilan Layar EkstrakurikulerPramuka 


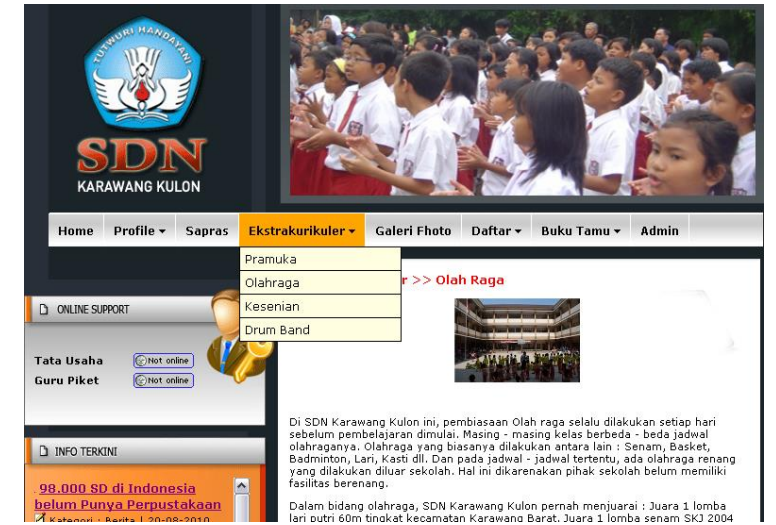

Gambar 10. Tampilan Layar EkstrakurikulerOlahraga

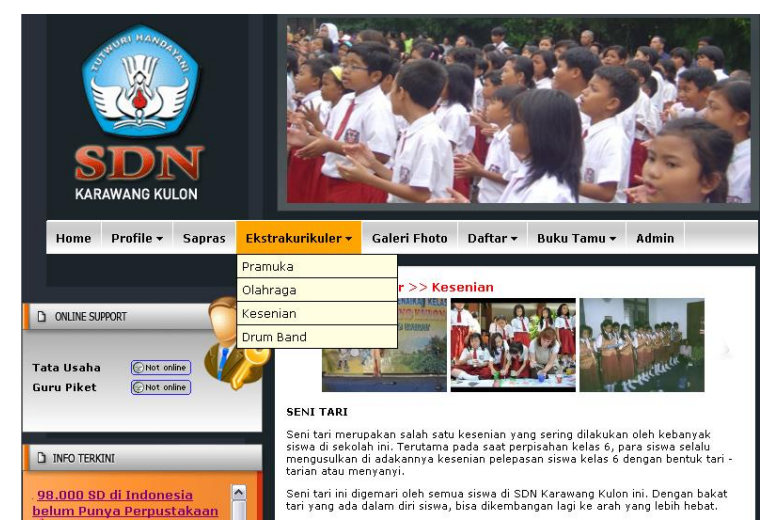

Gambar 11. Tampilan Layar Ekstrakurikuler-

Kesenian

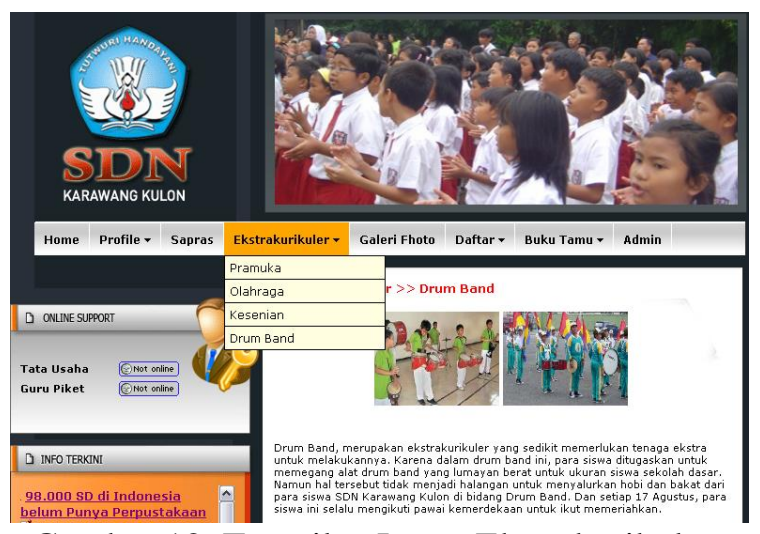

Gambar 12. Tampilan Layar EkstrakurikulerDrum Band

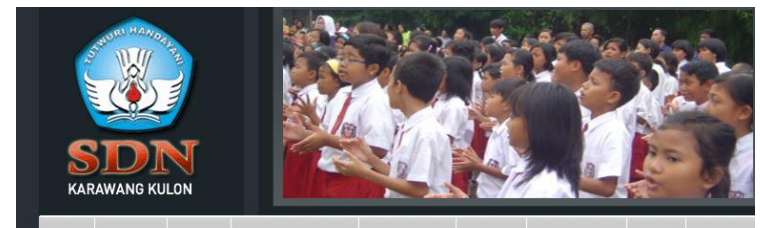

Home Profile - Sapras Ekstrakurikuler * Galeri Fhoto Daftar - Buku Tamu v Admin

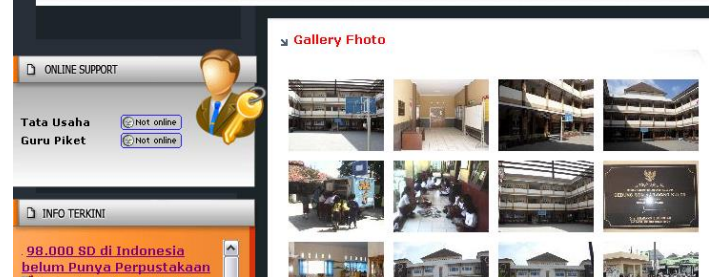

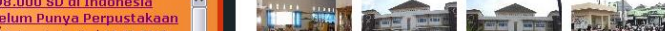

Gambar 13. Tampilan Layar Galeri Photo
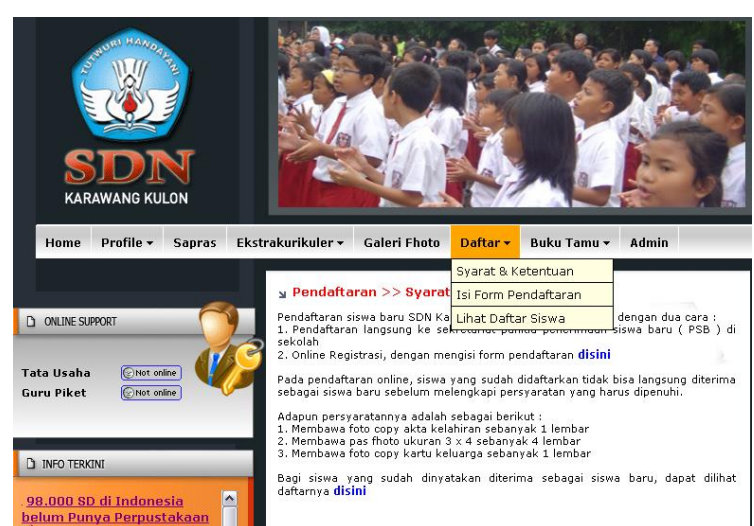

Gambar 14. Tampilan Layar Daftar-Syarat \& Ketentuan

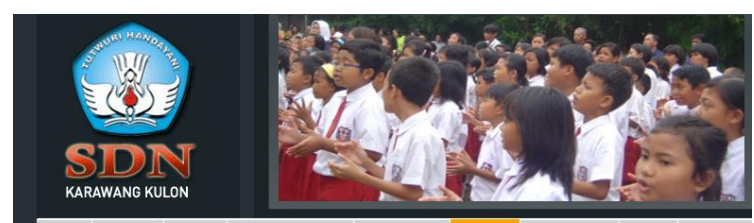

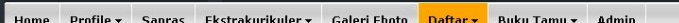

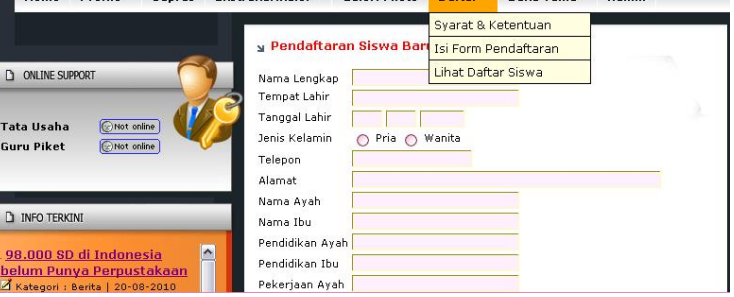

Gambar 15. Tampilan Layar Daftar-Isi Form Pendaftaran 


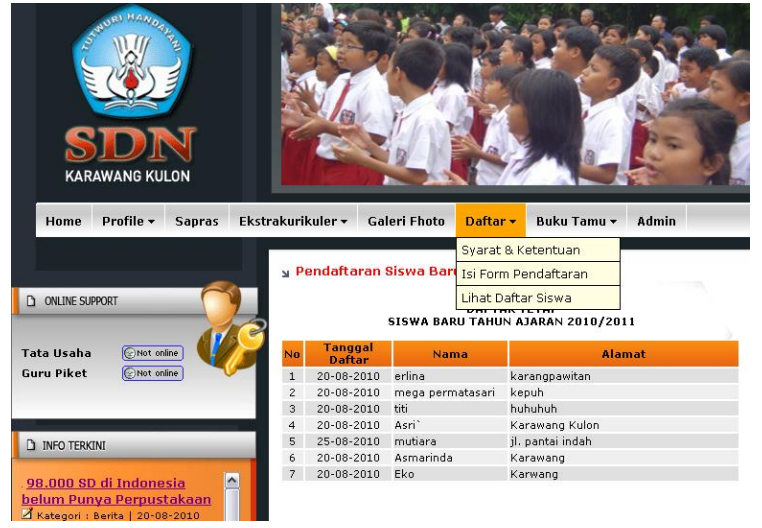

Gambar 16. Tampilan Layar Daftar-Lihat Daftar Siswa

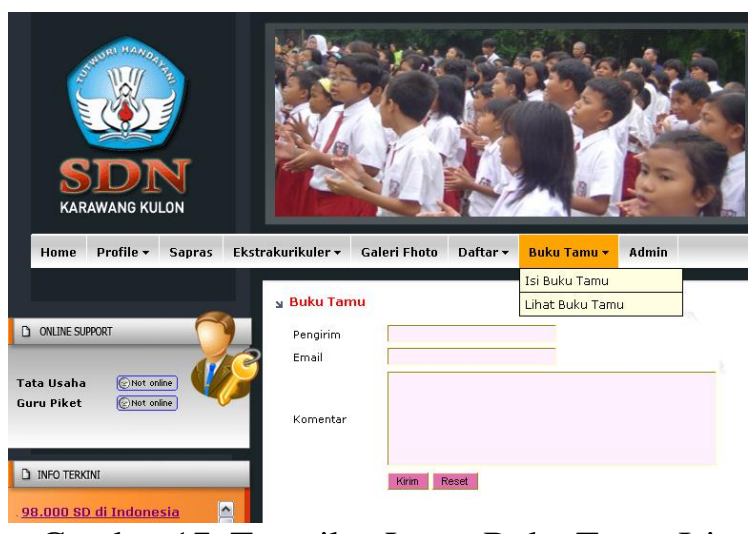

Gambar 17. Tampilan Layar Buku Tamu-Isi Buku Tamu

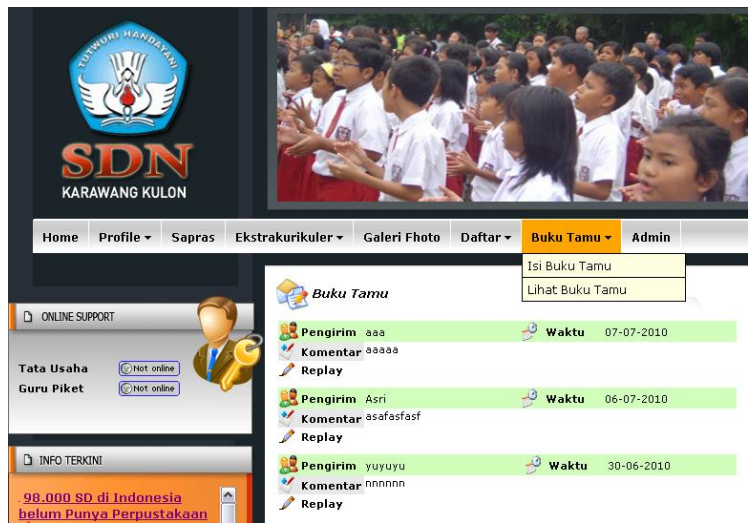

Gambar 18. Tampilan Layar Buku Tamu-Lihat Buku Tamu

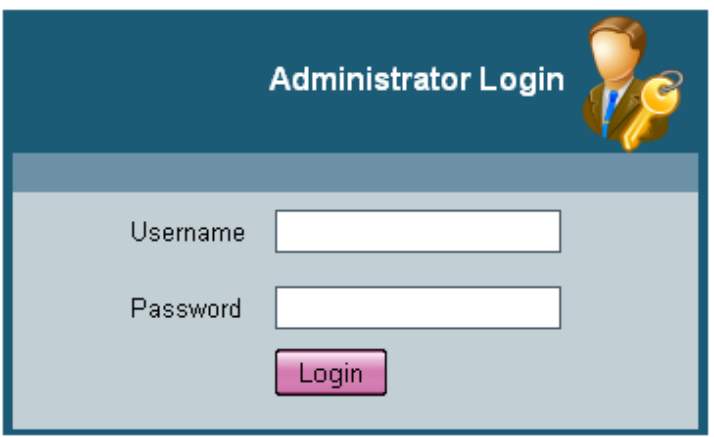

Gambar 19. Tampilan Layar Admin

\section{Kesimpulan dan Saran}

\section{Kesimpulan}

Setelah melakukan evaluasi dari website SDN Karawang Kulon, maka dapat disimpulkan bahwa dengan membangun sebuah website yang dipublikasikan di internet, ditemukan suatu strategi baru dalam penyampaian seputar SDN Karawang Kulon Karawang kepada masyarakat luas. Selain itu juga, bertujuan agar eksistensi SDN Karawang Kulon Karawang dapat diketahui oleh berbagai lapisan masyarakat dan seluruh warga sekolah SDN Karawang Kulon. Sehingga benar-benar bisa dijadikan sebagai sekolah dasar berstandar nasional.

Berdasarkan hasil survey dari implementasi website SDN Karawang Kulon, dapat dilihat bahwa penyampaian informasi kepada seluruh lapisan masyarakat dapat dilakukan secara optimal dan kebutuhan akan suatu informasi pun dapat diperoleh dengan cepat dan mudah. Oleh karena itu, dengan menggunakan Sistem Informasi sekolah dasar berbasiskan website maka diharapkan kebutuhan akan suatu informasi akan diperoleh secara cepat dan mudah, baik oleh kepala sekolah, siswa, guru, maupun masyarakat lainnya.

\section{Saran}

Adapun saran dari penulis untuk kepentingan pengembangan website SDN Karawang Kulon selanjutnya agar lebih sempurna yaitu :

1. Menyajikan informasi yang lebih menarik untuk mengundang perhatian pengunjung untuk menampilkan gambar-gambar, dalam jumlah yang sewajarnya. 
2. Melakukan pembaharuan data (update) secara berkala untuk menjaga agar website tetap up to date sehingga tidak membosankan bagi pengunjung.

3. Menambah fasilitas email untuk menampung surat-surat dari pengunjung

\section{Daftar Pustaka}

Jogiyanto., Analisis dan Desain Sistem Informasi, Andi OFFSET, Yogyakarta, 1990

Anonim, Pengantar Analisis dan Perancangan Sistem, Gunadarma, 1995

Sutedjo, Budi., Utomo Dharmo., Perancangan dan Pengembangan Sistem Informasi, Jakarta, 1992

Fathansyah, Ir., Basis Data, Bandung, 1999

Amsyah, Zulkifli., Manajemen Sistem Informasi, Gramedia Pustaka Utama, Jakarta, 2003

Oneto, Erima., Sudarya., Cara Cepat dan Mudah Membuat Website, Mediakita, Jakarta, 1995

Kristanto, Andri., Perancangan Sistem Informasi dan Aplikasnya, Gramedia, Jakarta, 2003 